\title{
APPLICATION OF MULTI LAYERED PERCEPTRON NEURAL NETWORK FOR MODELING BİODIESEL YIELD
}

\author{
SHANTHINI. A ${ }^{1} \&$ VINODHINI. G ${ }^{2}$ \\ ${ }^{l}$ Department of Information Technology, SRMIST, Kattankulathur, Chengalpattu District, Tamilnadu, India \\ ${ }^{2}$ Department of Information Technology, Annamalai University, Annamalai Nagar, Tamilnadu, India
}

\begin{abstract}
Biodiesel preparation is broadly led through transesterification process, with homogeneous or heterogeneous catalyst. The most remarkable catalyst utilized in preparing biodiesel is the homogeneous catalyst, for example, $\mathrm{NaOH}, \mathrm{KOH}, \mathrm{Na}_{2} \mathrm{O}_{2}$ and $\mathrm{CH}_{3} \mathrm{ONa}$. The decision of selecting among these catalysts is because of their higher response rates. Accordingly this paper examines the impacts of various catalyst utilized for preparing biodiesel using Mahua oil. Machine learning has demonstrated to be an amazing for various modeling during the previous decades. Multi Layered Perceptron based Artificial neural networks (ANN), stands out amongst the most prominent modeling methods investigated. The utilization of MLP for improvement of catalyst in bio diesel preparation was not well studied until ongoing decades. In this analysis, the focus is on the use of MLP based ANNs for catalysis advancement in biodiesel preparation. From the points of view of experimental analysis and ANN modeling, this investigation indicates how MLPs can be adequately connected for catalyst optimization in biodiesel preparation.
\end{abstract}

KEYWORDS: Artificial Neural Network; Biodiesel; Catalyst; Machine Learning

Received: Jun 08, 2020; Accepted: Aug 05, 2020; Published: Aug 18, 2020; Paper Id.: IJMPERDAUG202017

\section{INTRODUCTION}

The IC engines are widely utilized because of their efficient operation and economy. Since the petroleum reserves are depleting at a faster pace than ever before, there is an urgent need for an alternative renewable fuel. Biodiesel is considered to be a promising alternative fuel for diesel engines (sukuma et al 2020 and Sukumar et al 2015). Biodiseal is an oxygenated fuel made from vegetable oils and animal fats by converting triglycerides to esters (mainly methyl esters) by various processes of esterification. Biodiesel is made from edible palm oil, soybean oil, sunflower oil, coconut oil, rape seed oil and peanut oil (Silambarasan et al 2017). Availability of vast quantity of non-edible seeds and adequate wasteland can help production of biodiesel. The catalysts generally employed in transesterification method are homogeneous catalysts and heterogeneous catalysts. Ordinarily, homogeneous catalysts, for example, $\mathrm{NaOH}, \mathrm{KOH}, \mathrm{Na}_{2} \mathrm{O}_{2}$ and $\mathrm{CH}_{3} \mathrm{ONa}$ are all the more regularly utilized in preparing biodiesel than heterogeneous (Deivajothi et al 2019).The capacity of catalyst to perform under moderate conditions has prompted the decision of choosing the optimum catalyst.

Machine learning, a influential method of artificial intelligence (AI), has been widely used for classification, clustering and forecasting. In the past decades, it was widely utilized in many application fields, such as energy, biology, environment, medicine and engineering technology (Oguz et al 2013). However, in the literature reviewed there are not many studies that analyze the use of MLP based ANN modelling in catalyst 
optimization of Biodiesel preparation. So, this motivated to analyze the capability on application of ANN for optimization of catalysis in biodiesel preparation. The content of this paper comprises of various sections.

\section{LITERATURE REVIEW}

Cay et al (2013) shows that the ANN method can be used as an alternative to classical modelling techniques to accurately predict internal combustion engine efficiency, temperature and other parameters. Oguz et al ( 2010) has developed an artificial neural network, which was successfully used in the automotive sector as well as in several different fields of technology aimed at overcoming experimental difficulties, reducing cost, time and labor waste. Niu et al ( 2017) the predictive performance engine of ANN and SVM is tested and compared. This research indicates that SVM is well suited to diesel engine response predictions and should significantly reduce the experimental cost. Sai Bharadwaj et al ( 2019) compared oil production optimisation using the Artificial Neural Network ( ANN) modeling and Response Surface (RSM) methodology. The ANN with the Levenberg-Marquardt algorithm is used in rubber seed oil for optimisation in model network training. The mean square error (MSE) of $7.04 \times 10^{-4}$ and the determination coefficient R2 was 0.993 . Kumar et al (2019) studied was divided into two parts. A series of experiments were basically employed in the first part and the prediction is made using the artificial neural network ( ANN), in the second part. The predicted results were compared with the experimental results. An ANN model was developed using a learning algorithm based on back-propagation. The ANN model's R-square value was 0.9976.

\section{EXPERIMENTAL ANALYSIS}

The Alkali based catalysts for 10 gram of Potassium hydroxide (KOH), 8 gram of Sodium hydroxide $(\mathrm{NaOH}), 11 \mathrm{gram}$ of Sodium peroxide $\left(\mathrm{Na}_{2} \mathrm{O}_{2}\right)$ and 2.5 gram of $\mathrm{CH}_{3} \mathrm{ONa}$ the were utilized. The methanol was utilized as the alcohol. The optimization of reaction time was conducted in one litter of crude vegetable oil refinery waste (Mahua oil). The Optimization work was conducted in various reaction times with constant quantity of catalyst and alcohol. In both stage the ethanol was changed in the $200 \mathrm{ml}$. The alcohol catalyst was removed from the upper layer after the finish of response. Subsequently, the transesterified oil is washed with distilled water, before the remaining parts of the impetus have been evacuated and heated to remove water content.The figure 1 shows the experimental setup for biodiesel Plant.

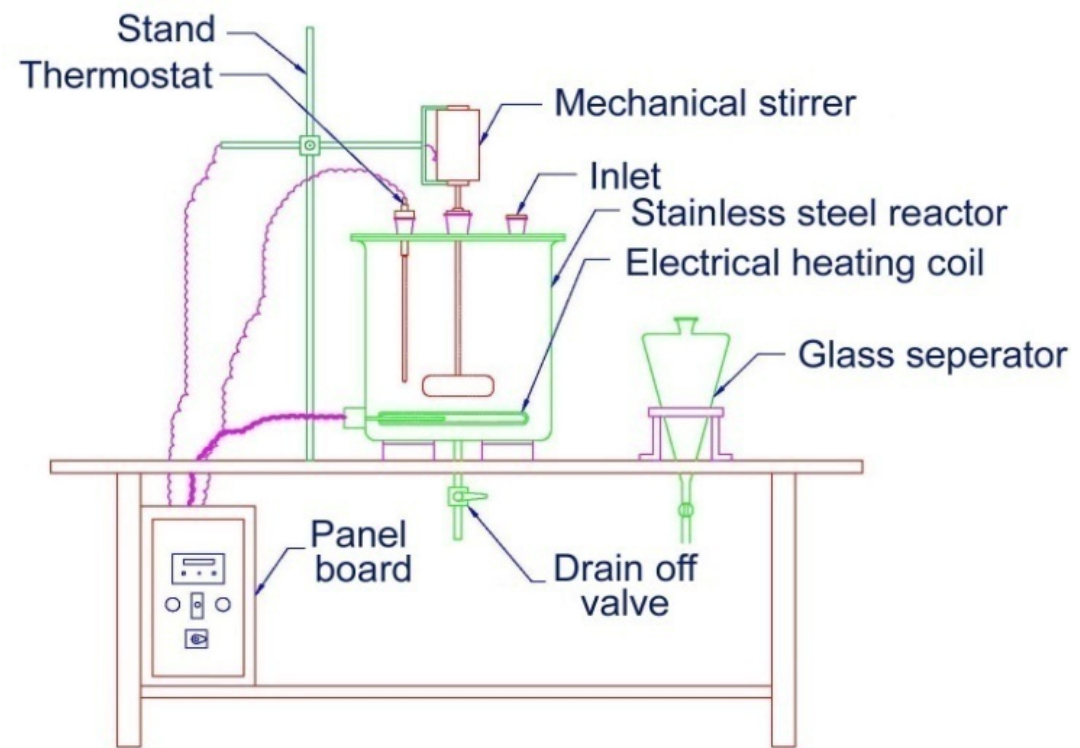

Figure 1: Experimental Setup for Biodiesel Plant. 
The yield of biodiesel for various catalysts with varying reaction time is analysed to find the optimum reaction of the catalyst. Different reaction times such as 30, 45, 60, 75 and 90 min were chosen for the analysis. The experimental results are tabulated in Table 1. In all the catalyst, when the reaction time was lower certain amount of soap formation is noted in the biodiesel Soaps were formed along with biodiesel, the soaps stick to the walls of the glass separator during the washing process. This formation of soaps reduces biodiesel yields. Among the catalyst used, the $\mathrm{KOH}$ and $\mathrm{CH}_{3} \mathrm{ONa}$ catalyst was found in optimum Yield. The higher biodiesel yield with minimum reaction time is obtained for $\mathrm{KOH}$ rather than $\mathrm{CH}_{3} \mathrm{ONa}$. Sodium hydroxide when used in the transesterification process increased the reaction time (Manieniyan et al 2016).

Table 1: Consolidation Results for Different Catalyst in Various Reaction Times

\begin{tabular}{|c|c|c|c|c|}
\hline Catalyst & $\begin{array}{l}\text { Catalyst Volume } \\
\text { of Ethanol in ML }\end{array}$ & $\begin{array}{c}\text { Weight of } \\
\text { Catalyst in Gms }\end{array}$ & $\begin{array}{l}\text { Reaction } \\
\text { Time in } \\
\text { Min }\end{array}$ & $\begin{array}{c}\text { Volume of Oil } \\
1 \text { Oil } \\
\text { (Biodiesel) \% } \\
\text { Actual }\end{array}$ \\
\hline \multirow{5}{*}{$\mathrm{NaOH}$} & 21 & 12 & 30 & 79 \\
\hline & 21 & 12 & 45 & 81 \\
\hline & 21 & 12 & 60 & 83 \\
\hline & 21 & 12 & 75 & 83 \\
\hline & 21 & 12 & 90 & 81 \\
\hline \multirow{5}{*}{ КОН } & 21 & 17 & 30 & 90 \\
\hline & 21 & 17 & 45 & 95 \\
\hline & 21 & 17 & 60 & 95 \\
\hline & 21 & 17 & 75 & 95 \\
\hline & 21 & 17 & 90 & 95 \\
\hline \multirow{5}{*}{$\mathrm{Na}_{2} \mathrm{O}_{2}$} & 21 & 11 & 30 & 50 \\
\hline & 21 & 11 & 45 & 52 \\
\hline & 21 & 11 & 60 & 58 \\
\hline & 21 & 11 & 75 & 58 \\
\hline & 21 & 11 & 90 & 58 \\
\hline \multirow{5}{*}{$\mathrm{CH}_{3}$ Ona } & 21 & 3 & 30 & 95 \\
\hline & 21 & 3 & 45 & 95 \\
\hline & 21 & 3 & 60 & 95 \\
\hline & 21 & 3 & 75 & 95 \\
\hline & 21 & 3 & 90 & 95 \\
\hline
\end{tabular}

\section{Multi Layered Perceptron}

The perceptrons with multiple layers (MLP) is a finite acyclic graph. The nodules are logistically powered neurons. The ith layer neurons act as input features for $i+1$ th layer neurons. Here you can calculate very complex functions, combining many neurons A MLP is an acyclic graph with finite directions. The nodes of any connections that are not the target are called input neurons. A MLP which is to be extended to dimension $\mathrm{n}$ input patterns must have $\mathrm{n}$ input neurons, one for each dimension. Generally, input neurons are enumerated as neurons 1 , neurons 2 , neurons $3, \ldots$ neuron $n$. The nodes that do not derive from any relation are called output neurons. An MLP can have more than one neuron for output. The number of output neurons depends on how the training patterns are represented for the target values (desired values). All the nodes which are either input neuron nor output neurons are called hidden neurons. As the graph is acyclic, all neurons can be grouped into layers, with the first layer being the collection of input layers. All connections are assigned with weights 
which are real numbers. The connection weight from node $\mathrm{i} \rightarrow \mathrm{j}$ is named wji. All hidden and output neurons have a bias weight. The bias weight of neuron $\mathrm{i}$ is named wi. The Fig 2 shows the steps in MLP.

1. Choose an initial weight vector $\mathrm{w}$

2. Initialize minimization approach

3. while error did not converge do

4. for all instances in dataset $D$ do

a. apply input $\mathrm{x}$ to network and calculate the network output

b. calculate partial derivative for all weights

5. end for

6. Calculate partial derivatives for all weights summing over all training patterns.

7. perform one update step of the minimization approach.

8. end while

Figure 2: MLP Steps.

\section{Modeling Evaluation}

An ANN model contains numerous input factors to predict different output factors. The well trained ANN is faster in prediction than the traditional mathematical models. In ANN modeling, no extensive iterative computations are needed as in mathematical modeling. However the determination of a optimimum neural network topology and its parameters for best prediction. In this investigation, MLP is utilized. MLP is a supervised learning method, for training Multi-layer Perceptrons. Fig 3 demonstrates the ANN model applied in this study.

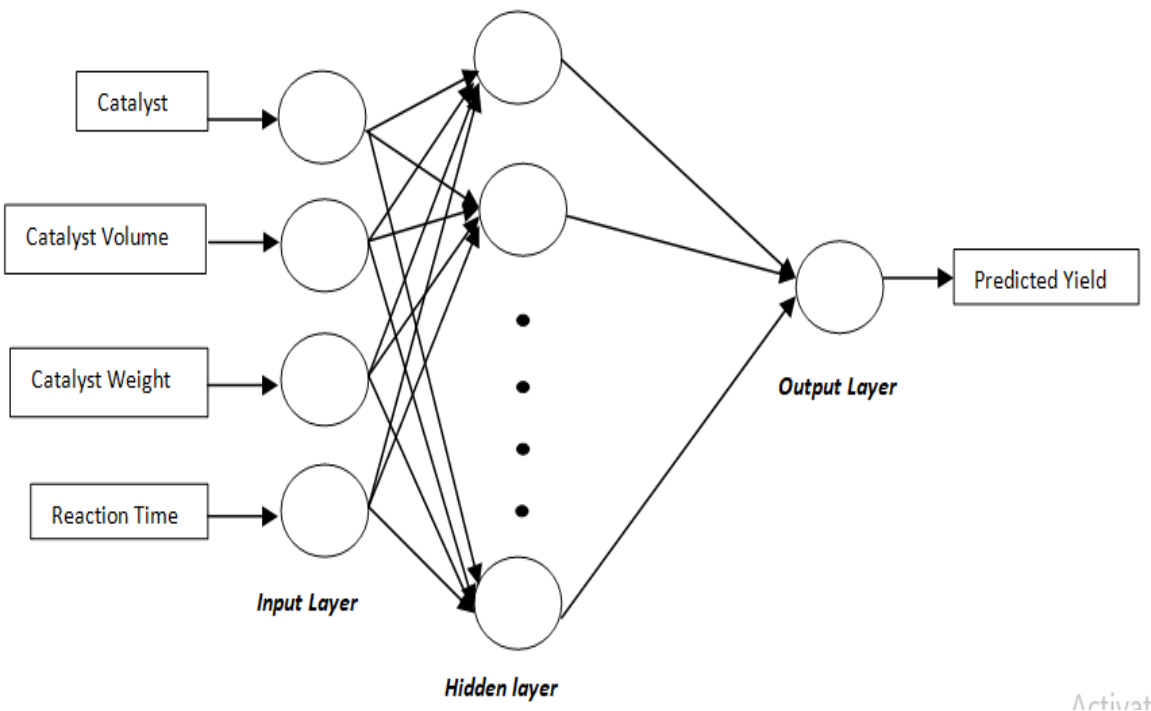

Figure 3: MLP Model Applied.

In this Modeling the number of input neurons is methanol quantity, catalyst quantity and reaction time. The yield of biodiesel is the output neuron. The parameters used in ANN model is as shown in Table 3. 
Table 2: ANN Parameters

\begin{tabular}{|l|c|}
\hline Number of input nodes & 4 \\
\hline Number of output nodes & 1 \\
\hline Number of hidden layers & 1 \\
\hline Number of hidden nodes & 5 \\
\hline Learning rate & 0.01 \\
\hline Activation function in hidden node & Relu \\
\hline Bias & 1 \\
\hline
\end{tabular}

The testing results for Biodiesel yield prediction Vs reaction time for catalyst optimization using ANN is obtained. The results are shown in Fig4 to Fig 7 for various catalysts used. These Figures clearly depicts that the yield prediction made by various catalyst are almost similar to the experimental yield obtained for varying reaction times applied during experimental analysis. In Fig 4 to Fig 7, the minimum deviation between exact values and predicted values of reaction time is because of the better generalization capacity of neural network model employed in this training and testing phase.A slightly higher variation is noted for $\mathrm{KOH}$ at the peak yield value this may be due to variation in the bias of the neural network model (Manieniyan et al 2013).
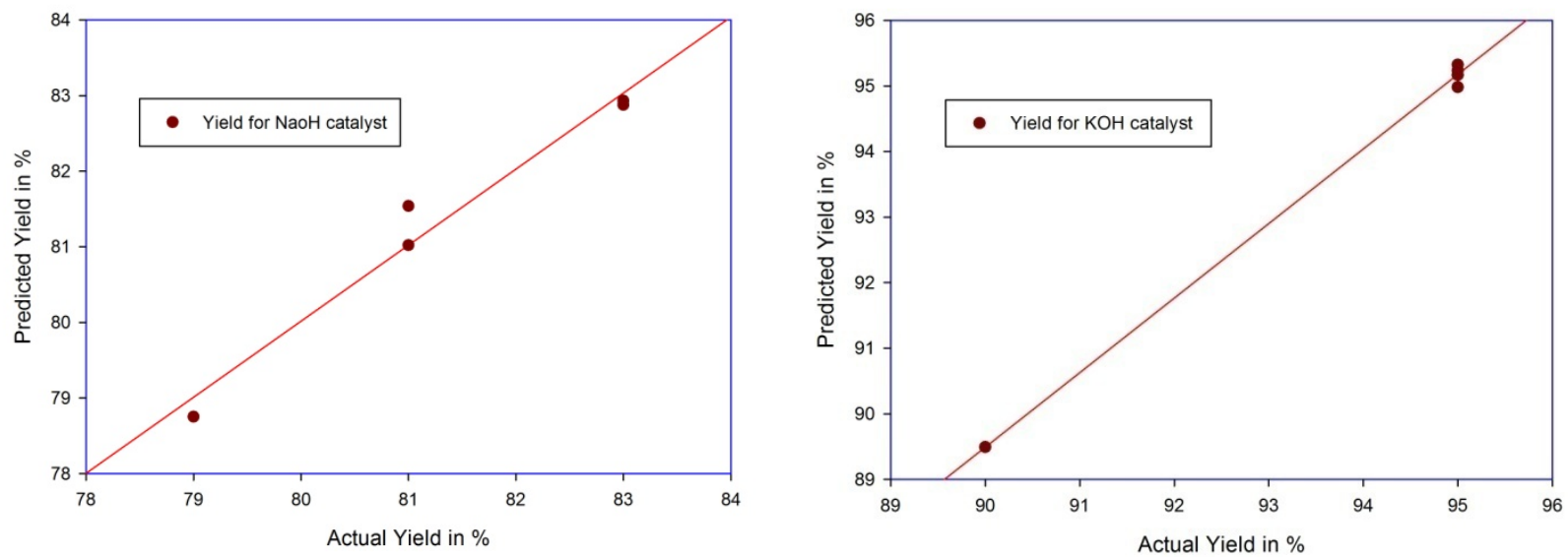

Figure 4: Scatter Plot of Actual Vs Predicted NAOH.
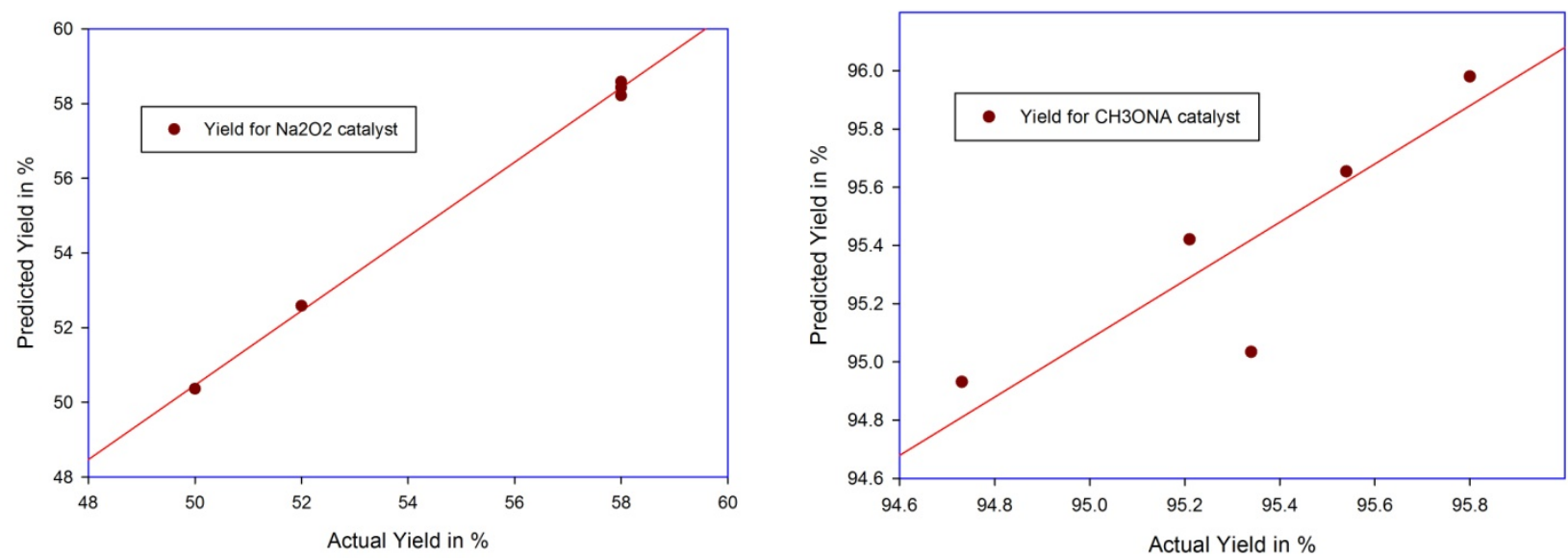

Figure 6: Scatter Plot of Actual Vs Predicted $\mathrm{Na}_{2} \mathrm{O}_{2}$.

Figure 7: Scatter Plot of Actual Vs Predicted $\mathrm{CH}_{3}$ Ona. 
Table 4: Regression Coefficient $\mathbf{R}^{2}$ Values

\begin{tabular}{|l|c|c|}
\hline Catalyst & R Square & Regression Equation \\
\hline $\mathrm{NAOH}$ & 0.968 & $\mathrm{Y}=-0.447+1.005 \mathrm{X}$ \\
\hline $\mathrm{KOH}$ & 0.997 & $\mathrm{Y}=-12.84+1.134 \mathrm{X}$ \\
\hline $\mathrm{Na}_{2} \mathrm{O}_{2}$ & 0.998 & $\mathrm{Y}=0.685+0.996 \mathrm{X}$ \\
\hline $\mathrm{CH}_{3}$ Ona & 0.996 & $\mathrm{Y}=-0.754+1.025 \mathrm{X}$ \\
\hline
\end{tabular}

The regression coefficient $R^{2}$ values shown in Table 4 reveals that for all catalysts employed the MLP modeling results in maximum $\mathrm{R}^{2}$ values of range 0.97 to 0.998 . Also the egression equation is also shown for each catalyst in the table 4. Thus it is concluded that ANN modeling using MLP can be used as an effective tool for modeling of catalyst optimization in biodiesel production.

\section{CONCLUSIONS}

In this study the effect of various catalysts such as $\mathrm{NaOH}, \mathrm{KOH}, \mathrm{Na}_{2} \mathrm{O}_{2}$ and $\mathrm{CH}_{3} \mathrm{ONa}$ were analyzed in bio diesel production. The bio diesel production is carried out by transesterification process using crude vegetable oil refinery waste. In order to identify the optimum catalyst, various reaction times are used in the experimental analysis. The optimum catalyst used in producing biodiesel is $\mathrm{KOH}$. In order to show the effectiveness of ANN modeling, MLP model is used in this study. The results concluded that MLP based ANN modeling can be used as an effective tool for modeling of catalyst optimization in biodiesel production.

\section{REFERENCES}

1. Balabin, Roman M., Ekaterina I. Lomakina, and Ravilya Z. Safieva, (2011) "Neural network (ANN) approach to biodiesel analysis: analysis of biodiesel density, kinematic viscosity, methanol and water contents using near infrared (NIR) spectroscopy." Fuel 90, no. 5: 2007-2015.

2. Oguz, Hidayet, Ismail Sarıtas, and Hakan Emre Baydan, (2010) "Prediction of diesel engine performance using biofuels with artificial neural network." Expert Systems with Applications 37, no. 9: 6579-6586.

3. Cay, Yusuf, (2013), "Prediction of a gasoline engine performance with artificial neural network." Fuel 111: 324-331.

4. Niu, Xiaoxiao, Chuanlei Yang, Hechun Wang, and Yinyan Wang, (2017) "Investigation of ANN and SVM based on limited samples for performance and emissions prediction of a CRDI-assisted marine diesel engine." Applied Thermal Engineering 111 1353-1364.

5. Sai Bharadwaj, A. V. S. L., and KM Meera S. Begum, (2019) "Free fatty acid optimization and modeling of biodiesel production from high viscous rubber seed oil-A comparative study of RSM and ANN." Energy Sources, Part A: Recovery, Utilization, and Environmental Effects 1-15.

6. Kumar, Sunil, Siddharth Jain, and Harmesh Kumar, (2019) "Prediction of jatropha-algae biodiesel blend oil yield with the application of artificial neural networks technique." Energy Sources, Part A: Recovery, Utilization, and Environmental Effects 41, no. 11: 1285-1295. 
7. V.Manieniyan and S.Sivaprakasam, (2013) "Artificial Neural Network Based Modelling for Vibration Characteristics of DI Diesel Engine Using Bio-Diesel”, International Journal of Advanced Research in Computer Science and Software Engineering, 3, 8634-638.

8. Manieniyan, V., Vinodhini, G., Senthilkumar, R., \& Sivaprakasam, S. (2016). Wear element analysis using neural networks of a DI diesel engine using biodiesel with exhaust gas recirculation. Energy, 114, 603-612.

9. Deivajothi, P., Manieniyan, V., \& Sivaprakasam, S. (2019). Experimental investigation on DI diesel engine with fatty acid oil from by-product of vegetable oil refinery. Ain Shams Engineering Journal, 10(1), 77-82.

10. Sukumar, V., V. Manieniyan, R. Senthilkumar, and S. Sivaprakasam, (2020) "Production of bio oil from sweet lime empty fruit bunch by pyrolysis." Renewable Energy 146: 309-315.

11. Sukumar, V., V. Manieniyan, and S. Sivaprakasam, (2015) "Bio oil production from biomass using pyrolysis and upgrading-A review." International Journal of ChemTech Research 8, no. 1: 196-206.

12. Silambarasan, R., V.Manieniyan, R Senthilkumar, and S Sivaprakasam, (2017)"Performance and Emission Analysis in DI Diesel Engine Using Biodiesel with Bio Additive. " International Journal of Engineering Trends and Technology (IJETT), 04 (05) 865-868. 
